\title{
25. MAGNETIC VISCOSITY OF LEG 46 BASALTS
}

\author{
Brigitte M. Smith, Laboratoire de Géomagnétisme, Université de Paris VI, \\ 4 Avenue de Neptune, 94100 Saint-Maur, France
}

\section{INTRODUCTION}

A test of magnetic viscosity was performed on 40 samples of basaltic rocks ( 30 minicores and 10 slabs) randomly taken between 150 and 330 meters below the sea floor in Hole 396B. The samples are of fresh as well as altered material.

The experiment consisted of measuring the remanent viscous magentization, VRM $\left(t, h, t^{\prime}\right)$, of a rock; that is, the magnetization acquired during an interval of time $t$ in a low steady field $h$ and measured at a time $t^{\prime}$ after the sample is removed from this field. The purpose of this study is to test the ability of oceanic basalts to acquire a VRM; this is part of a synthetic study whose object is the statistical comparison of the magnetic viscosity of oceanic basaltic rocks between several sites of different ages, and how it relates to alteration of these basalts. The present results are preliminary; more definitive conclusions await further measurements of other DSDP basalts.

\section{PROCEDURE}

The samples are left in the earth's magnetic field $\overrightarrow{(H)}$ in the laboratory, with one of the reference axes $(\overrightarrow{X)}$ parallel to $\vec{H}$.

Measurements of the remanent magnetization are made (1) after a stay of 14 days with $+\vec{X}$ along $\vec{H}$, and (2) after a second stay of 14 days in the reverse position, with $-\vec{X}$ along $\vec{H}$.

The viscosity coefficient $v$ is defined according to Thellier's method (Thellier, 1959; Prévot, 1975) as follows:

$$
v=\frac{\overrightarrow{\text { VRM lab }}}{\text { stable } \overrightarrow{\text { NRM }}} \times 100
$$

$$
\text { and stable } \overrightarrow{\mathrm{NRM}}=\overrightarrow{\mathrm{PRM}}+\text { in situ } \overrightarrow{\mathrm{VRM}} \text {. }
$$

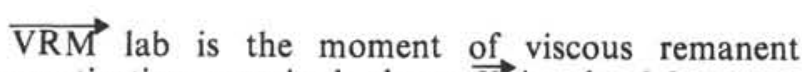
magnetization acquired along $\vec{X}$ in the laboratory during the 14-day experiment:

$\overrightarrow{\mathrm{VRM}}$ lab (14 days, $H$ lab, few minutes).

The VRM component acquired along $X$ is defined as half the difference between the normal and reverse corresponding components, the $Y$ and $Z$ components remaining the same for the two sample positions.

Stable $\overrightarrow{N R M}$ is the moment of natural remanent magnetization defined as the sum of the initial primary remanent magnetization $\overrightarrow{\text { PRM}}$, and the $\overrightarrow{\mathrm{VRM}}$ acquired in situ from 700,000 years to the present, just before starting the viscosity experiment, where in situ VRM is (700,000 years, earth field, 1 month). Each of the stable NRM components is half the sum of the corresponding normal and reverse components.

\section{RESULTS}

Values of the stable NRM intensity $J_{r}$, viscosity coefficient $v$ and intensity of the 14 day VRM's $J_{\nu}$ are summarized in Table 1 and illustrated in Figure 1 (a, b, and c), where a logarithmic plot is used.

TABLE

Magnetic Viscosity Results

\begin{tabular}{llll}
\hline $\begin{array}{c}\text { Sample } \\
\text { (Interval in cm) }\end{array}$ & $\begin{array}{c}J_{r}^{\mathrm{a}} \\
\left(10^{-3} \mathrm{emu}^{\mathrm{ccc}}\right)\end{array}$ & $\begin{array}{c}\nu^{\mathrm{b}} \\
(\%)\end{array}$ & $\begin{array}{c}J_{\nu}{ }^{\mathrm{c}} \\
\left(10^{-5} \mathrm{emu} / \mathrm{cc}\right)\end{array}$ \\
\hline 5-1-9, 78-80 & 0.70 & 1.6 & 1.17 \\
$7-2-5,42-45$ & 0.41 & 1.9 & 0.78 \\
$7-2-7 \mathrm{~B}, 73-75$ & 1.78 & 1.1 & 1.89 \\
$8-1-10,90-92$ & 1.00 & 1.3 & 1.26 \\
$8-2-4 \mathrm{~B}, 41-43$ & 2.37 & 0.97 & 2.28 \\
$9-1-6 \mathrm{D}, 40-43$ & 0.43 & 5.8 & 2.51 \\
$9-1-13,98-100$ & 0.41 & 2.3 & 0.95 \\
$9-2-2,14-16$ & 0.59 & 0.77 & 0.43 \\
$9-3-2 \mathrm{~A}, 14-16$ & 1.00 & 3.7 & 3.62 \\
$11-1-10 \mathrm{~B}, 97-99$ & 1.35 & 2.2 & 2.95 \\
$11-2-2,18-20$ & 2.37 & 1.8 & 4.24 \\
$12-1-7,110-112$ & 2.80 & 1.7 & 4.89 \\
$13-14 \mathrm{~A}, 37-39$ & 0.24 & 3.3 & 0.78 \\
$13-1-5 \mathrm{C}, 84-86$ & 1.11 & 1.4 & 1.59 \\
$14-1-5 \mathrm{~B}, 34-36$ & 1.13 & 0.75 & 0.82 \\
$14-2-11,113-115$ & 1.02 & 2.7 & 2.76 \\
$14-3-5 \mathrm{C}, 70-72$ & 1.83 & 2.3 & 4.15 \\
$15-1-4,22-24$ & 0.69 & 1.9 & 1.29 \\
$15-2-15,79-81$ & 8.70 & 4.2 & 36.64 \\
$15-4-7,114-116$ & 31.44 & 2.3 & 71.84 \\
$15-5-2 \mathrm{~B}, 16-18$ & 8.01 & 0.60 & 4.81 \\
$16-1-4,28-30$ & 3.54 & 0.85 & 3.02 \\
$16-1-12,110-112$ & 0.56 & 1.5 & 0.79 \\
$16-2-2,21-23$ & 1.14 & 1.6 & 1.88 \\
$16-3-4 \mathrm{~B}, 34-41$ & 0.84 & 1.9 & 1.51 \\
$16-4-14,112-114$ & 0.41 & 2.9 & 1.17 \\
$17-4-1,11-13$ & 2.08 & 0.55 & 1.13 \\
$18-14 \mathrm{~A}, 43-45$ & 0.92 & 1.1 & 1.01 \\
$18-1-4 \mathrm{C}, 55-57$ & 3.44 & 0.38 & 1.27 \\
$20-1-4,65-69$ & 3.46 & 0.64 & 2.19 \\
$20-2-9,97-99$ & 0.83 & 1.8 & 1.54 \\
$20-3-16,127-129$ & 1.38 & 1.2 & 1.69 \\
$20-5-9 \mathrm{~B}, 76-78$ & 0.49 & 3.1 & 1.49 \\
$20-5-9 \mathrm{C}, 84-93$ & 2.65 & 0.60 & 1.59 \\
$21-1-10,80-91$ & 3.00 & 1.2 & 3.73 \\
$21-2-2,16-24$ & 2.73 & 0.99 & 2.70 \\
$22-2-3 \mathrm{C}, 61-75$ & 3.16 & 0.75 & 2.38 \\
$22-2-7 \mathrm{C}, 110-120$ & 2.67 & 2.2 & 5.94 \\
$22-3-7 \mathrm{~B}, 104-117$ & 4.62 & 1.3 & 8.26 \\
$24-1-9,51-53$ & 2.18 & 0.68 & 1.44 \\
\hline & & & \\
\hline
\end{tabular}

$\mathrm{a}_{J_{r}}$ : intensity of stable natural remanent magnetization (see text).

$b_{v}$ : viscosity coefficient for a 14-day experiment in the earth magnetic field.

$\mathrm{c}_{J_{v}}$ : intensity of the viscous remanent magnetization acquired during 14 days in the earth's magnetic field. 

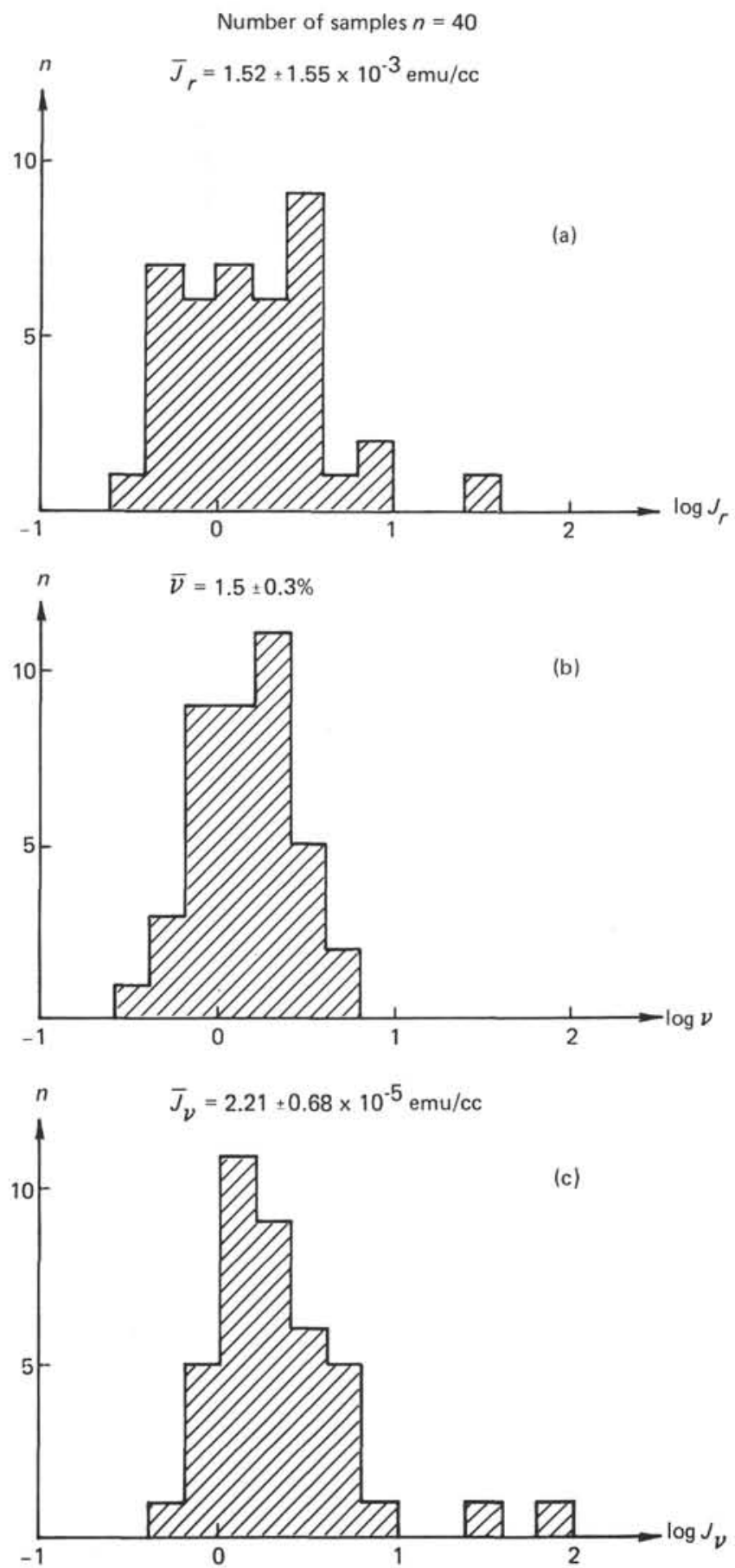

Figure 1. Histograms of stable NRM intensity $\left(\mathrm{J}_{\mathrm{r}}\right)$, viscosity coefficient $(v)$ and 14-day VRM intensity $\left(J_{v}\right)$ for analyzed samples.

(1) The mean stable NRM is $J_{r}=1.52 \pm 1.55 \times 10^{-3}$ emu/cc ( $95 \%$ confidence interval).

(2) The mean value of $\mathrm{v}$ is $\bar{v}=1.45 \pm 0.28 \%(95 \%$ confidence interval).

(3) The mean VRM intensity is $\bar{J}_{v}=2.21 \pm 0.68 \times$ $10^{-5} \mathrm{emu} / \mathrm{cc}$ ( $95 \%$ confidence interval).

It can be seen that the magnetic viscosity is always very low, but seems to be slightly higher than the values obtained on the youngest fresh basalts from the FAMOUS area.

\section{REFERENCES}

Thellier, E., 1959. Sur l'intensité du champ terrestre dans le passé historique et géologique: Ann. Geophys., v. 15, p. 285-376.

Prévot, M., 1975. Magnétisme et minéralogie magnétique de roches néogènes et quaternaires, contribution au paléomagnétisme et à la géologie du Velay: Thèse, Université de Paris VI, p. 165-173. 